\title{
An Exploration of How People with Mobility Disabilities Rate Community Barriers to Physical Activity
}

\author{
Vijay Vasudevan \\ Department of Health Outcomes and Policy, University of Florida
}

\begin{abstract}
Background and Significance: People with mobility disabilities (such as people who use a cane, walker, or wheelchair) are less likely to be physically active. Previous studies have identified community barriers to physical activity. However, these studies did not measure how people with mobility disabilities rated community barriers to physical activity. This study examined how people with mobility disabilities rate community barriers and explore relationships between these barriers and engagement in physical activity.

Methods: Study participants $(\mathrm{n}=150)$ were recruited from an accessible fitness center and an independent living center. Participants completed the Barriers to Physical Activity Questionnaire for People with Mobility Impairments and the Physical Activity and Disability Survey. Results: The most frequently reported community barriers were excessive crime or fear of crime (40.7\%) and cars driving too fast (40.7\%). The highest rated barrier was lack of accessible transportation to a fitness center, with a median rating of 5 out of 5 . There was a significant, negative correlation between strength exercise and built environment and perceptions of safety. There was no significant correlation between aerobic exercise and built environment and perceptions of safety. Conclusion: People with disabilities face community barriers which contribute to a disparity in opportunities to be physically active. Future intervention studies are needed to determine whether physical activity rates change after improvements are made to make physical activity more accessible for people with disabilities.
\end{abstract}

(c) 2016 Californian Journal of Health Promotion. All rights reserved.

Keywords: Disability; Community Barriers; Exercise; Physical Activity; Built Environment

\section{Introduction}

The World Health Organization defines disability as the complex interaction between an individual's impairment, activity limitation, participation restrictions, health, and personal and community factors (World Health Organization, 2001). Approximately 20\% of adults in the United States ( $\sim 53$ million adults) have some disability, with mobility disability being the most frequently reported disability type (13.0\%) (Courtney-Long et al., 2015). People with disabilities are a relatively unrecognized population with health disparities (Krahn, Walker, \& Correa-De-Araujo, 2015). People with disabilities have increased odds of having chronic health conditions such as obesity, hypertension, diabetes, and cancer (Dixon-Ibarra \& Horner-Johnson, 2014). Physical activity has been shown to reduce the risk for these chronic health conditions (Centers for Disease Control and Prevention, 2015). When compared to people without disabilities, a greater proportion of people with disabilities reported being physically inactive (26.1\% versus $47.1 \%)$ (Carroll et al., 2014).

Community factors such as a built environment that is conducive to physical activity and perceptions of neighborhood safety, play an integral role in promoting or inhibiting physical activity for people with disabilities (Brownson, Baker, Housemann, Brennan, \& Bacak, 2001). Studies have identified community barriers to physical activity including: opportunities, aesthetic attributes, weather, safety, availability and condition of built environment features, land use mix, and open space (Botticello, Rohrbach, \& Cobbold, 2014; Rosenberg, Huang, Simonovich, \& Belza, 2013). These studies either used qualitative methods to identify 
barriers, or did not include people with disabilities in their study's population.

The only known study that assessed the relationship between how people with disabilities perceive their neighborhood and their levels of physical activity was conducted by Christensen (2010), who analyzed data from the Texas Behavioral Risk Factor Surveillance System (BRFSS). In this study there was no association between perceived neighborhood ratings and physical activity levels. The BRFSS items that were used had dichotomous response options which limited the study respondents from providing more calibrated ratings of barriers to physical activity, and the BRFSS items did not include a detailed list of community barriers. For example, the BRFSS had only one item that asked about the presence or absence of sidewalks. No information was collected regarding the quality of the sidewalks that can pose as barriers to disabled individuals, such as the presence of cracks, gaps, and how uneven the sidewalks are.

The purposes of this study were to: (1) examine how people with disabilities rate a detailed list of community barriers to physical activity and (2) explore the potential relationship between physical activity and community barriers. By understanding how people with disabilities rate community barriers to physical activity, researchers, public health professionals, and urban planners can develop communities that are supportive of physical activity for everyone regardless of disability status.

\section{Methods}

This study was approved by the Institutional Review Board at the University of Illinois at Chicago. Informed, written consent was received from all study participants prior to their participation. This study utilized a crosssectional design. Participants completed three questionnaires in person, which took approximately 30 to 45 minutes to complete in total.

\section{Participants}

A convenience sample was recruited from two locations in Chicago, Illinois: 75 participants were recruited from a fitness center that is accessible for people with disabilities, and 75 were recruited from a large, urban independent living center in Chicago, Illinois. The inclusion criteria were: (1) 18 years of age or older; (2) self-reported difficulty walking a quarter mile or climbing ten steps without using cane, walker, or wheelchair; and (3) lived in Chicago.

\section{Measures}

Participants completed three questionnaires: the Barriers to Physical Activity Questionnaire for People with Mobility Impairments (BPAQ-MI), the Physical Activity and Disability Survey (PADS), and a demographic questionnaire.

The BPAQ-MI is a reliable, valid questionnaire that was developed to measure perceived barriers to physical activity from an ecological perspective (Vasudevan, Rimmer, \& Kviz, 2015). The domains and constructs that the BPAQ-MI measured included: intrapersonal barriers (perceptions of health and attitudes/beliefs towards physical activity), interpersonal barriers (friends and family), organizational barriers (built environment of a fitness center and staff/equipment/policy), and community barriers (built environment and perception of safety). For the purposes of this study, only the community barrier domain was examined. There are 10 items in the built environment construct $(\alpha=0.879)$ and six items in the perception of safety construct $(\alpha=0.793)$. Study participants were asked whether or not they experienced a barrier within the past three months. If the respondent answered "yes," they were then asked to rate the barrier on a scale of one to five where one was a "small barrier" and five was a "large barrier". An open-ended item to identify additional barriers was not included, because during the development of the BPAQMI, Delphi panelists believed that an openended item would excessively burden the participants.

The PADS questionnaire was developed to measure the type and duration of physical activity and was validated on a sample of people 
with mobility impairments (Rimmer, Riley, \& Rubin, 2001). For this study, physical activity was defined using the Center for Disease Control and Prevention's (CDC) definition of aerobic exercise (activities that are done for sustained periods that result in an increased heart rate) and strength exercise (exercises that use resistance to cause muscle contraction, which include but is not limited to weight lifting or elastic bands) (Centers for Disease Control and Prevention, 2011). The CDC recommends everyone regardless of disability status to perform at least 150 minutes per week of aerobic exercise and two days per week of strength exercise (Centers for Disease Control and Prevention, 2009). Therefore minutes of aerobic exercise per week was estimated by multiplying the number of days per week by minutes per day for each activity, and strength exercise was estimated by summing the number of days per week respondents did strength exercises.

Participants also answered demographic questions regarding: age, gender, race, education, income range, disability, use of a mobility device, and height/weight.

\section{Analyses}

Data analysis was conducted using STATA version 14.0 (StataCorp, 2015). Frequencies and percentages for the presence of each community barrier to physical activity were calculated. . Next, the median and interquartile range (IQR) was calculated for each barrier, for those participants who reported the presence of that barrier in the previous question. Spearman's rank correlations were performed to explore the relationship between community barriers and physical activity. Comparisons were not made between those who reported using a wheelchair, a cane, or a walker on community barrier ratings because of the heterogeneity in the number of mobility devices that participants used.

\section{Results}

The majority of participants were African American (73.3\%) and female (55.4\%). The mean age was 55.2 years old (standard deviation $(\mathrm{SD})=11.9)$, and the mean body mass index was $30.4 \mathrm{~kg} / \mathrm{m}^{2}$ (SD = 9.4). The majority of participants used a cane (50.7\%) and approximately a third used a wheelchair (36.7\%) or a walker (30.0\%). The majority of study participants had some college education (61.3\%), approximately a quarter (24.7\%) graduated high school, and $14.0 \%$ had less than a high school education. Nearly two-thirds of participants' income (69.3\%) was less than $\$ 15,000$ per year, $11.3 \%$ had an annual income between $\$ 15,000$ and $\$ 20,000$, and $19.4 \%$ had an annual income greater than $\$ 20,000$.

\section{Table 1}

Community Barrier Frequency and Mean Rating for Participants who Experience Barrier $(\mathrm{N}=150)$

\begin{tabular}{|c|c|c|}
\hline & n (\%) & Median (IQR) \\
\hline Built Environment & & \\
\hline $\begin{array}{l}\text { Lack of access to public } \\
\text { restrooms }\end{array}$ & 55 (36.7) & $4(3-5)$ \\
\hline Lack of rest areas (e.g. & $52(34.7)$ & $4(4-5)$ \\
\hline Benches) & & \\
\hline $\begin{array}{l}\text { The sidewalks have } \\
\text { cracks, gaps, or are under } \\
\text { construction }\end{array}$ & $52(34.7)$ & $4(3-4)$ \\
\hline $\begin{array}{l}\text { Potholes in the street, } \\
\text { driveways, or parking lot }\end{array}$ & 46 (30.7) & $4(3-5)$ \\
\hline $\begin{array}{l}\text { Uneven or crooked } \\
\text { sidewalks }\end{array}$ & $45(30.0)$ & $4(3-5)$ \\
\hline $\begin{array}{l}\text { Sidewalk's cross slope is } \\
\text { too steep/slanted }\end{array}$ & $45(30.0)$ & $4(3-5)$ \\
\hline $\begin{array}{l}\text { The crosswalks lack } \\
\text { traffic lights }\end{array}$ & $39(26.0)$ & $3(2-5)$ \\
\hline $\begin{array}{l}\text { Lack of accessible } \\
\text { transportation to fitness } \\
\text { center }\end{array}$ & 37 (24.7) & $5(4-5)$ \\
\hline $\begin{array}{l}\text { Lack of accessible curb } \\
\text { cuts in community }\end{array}$ & $36(24.0)$ & $4(3-5)$ \\
\hline $\begin{array}{l}\text { Sidewalks were not wide } \\
\text { enough }\end{array}$ & $27(18.0)$ & $4(3-5)$ \\
\hline Safety & & \\
\hline $\begin{array}{l}\text { Excessive crime or fear of } \\
\text { crime in neighborhood }\end{array}$ & $61(40.7)$ & $4(3-5)$ \\
\hline The cars drive too fast & $61(40.7)$ & $4(3-5)$ \\
\hline $\begin{array}{l}\text { Excessive car traffic in } \\
\text { my community }\end{array}$ & $55(36.7)$ & $4(3-5)$ \\
\hline $\begin{array}{l}\text { The traffic lights or } \\
\text { crosswalk signals change too } \\
\text { quickly }\end{array}$ & $49(32.7)$ & $4(3-5)$ \\
\hline $\begin{array}{l}\text { Lack of adequate street } \\
\text { lighting at night }\end{array}$ & 37 (24.7) & $4(3-5)$ \\
\hline Loose dogs in community & $25(16.7)$ & $3(2-5)$ \\
\hline
\end{tabular}

The most frequently reported community barriers were "excessive crime or fear of crime in neighborhood" (40.7\%) and "cars driving too fast" $(40.7 \%)$. The highest rated barrier was "lack of accessible transportation to a fitness 
center" with a median rating of 5 . The lowest rated barriers with a median rating of 3 included: "the crosswalks lacked traffic lights" and "presence of loose dogs in the community." Table 1 describes the frequency, median, and IQR of every barrier for participants who experienced that barrier.

Five outliers were removed, because their exercise totals were more than two standard deviations above the mean. On average, participants performed aerobic exercise for 112.5 minutes/week and performed strength exercises approximately 1.5 days/week.

Table 2 describes the Spearman rank correlation between community barrier domains and type of exercise. There was a significant, negative correlation between days per week of strength exercise and both community barrier constructs. There was no significant correlation between aerobic exercise and either community barrier construct.

Table 2

\begin{tabular}{ccc}
\hline \multicolumn{3}{r}{$\begin{array}{c}\text { Correlation between Community Barriers } \\
\text { and Types of Exercise }(\mathrm{n}=145)\end{array}$} \\
\hline \multicolumn{3}{c}{$\begin{array}{c}\text { Built } \\
\text { Environment }\end{array}$} \\
$\begin{array}{c}\text { Aerobic } \\
\text { (min/week) }\end{array}$ & -0.060 & $-0.152^{\#}$ \\
$\begin{array}{c}\text { Strength } \\
\text { (days/week) }\end{array}$ & $-0.171^{*}$ & $-0.267^{* *}$ \\
${ }^{\#} \mathrm{p}<0.10,{ }^{*} \mathrm{p}<0.05,{ }^{* *} \mathrm{p}<0.01$ &
\end{tabular}

\section{Discussion}

This study is one of the first to assess how people with mobility impairments rate community barriers to physical activity. The most frequently reported community barriers were: excessive crime or fear of crime, cars driving too fast, and excessive car traffic. The highest rated barrier was lack of accessible transportation to a fitness center. While none of the barriers had a frequency reported greater than $41 \%, 14$ out of 16 barriers had a median rating of at least 4 . This means that when a barrier exists for people with disabilities, it was generally rated between 3 and 5 on the BPAQMI scale.
Previous studies used questionnaires that were designed to measure the accessibility of a community (Gray, Zimmerman, \& Rimmer, 2012). Questionnaires have been developed that attempt to measure how inclusive communities are towards people with disabilities in community health initiatives (Eisenberg, Rimmer, Mehta, \& Fox, 2015). However these accessibility and inclusivity questionnaires did not measure how people with disabilities rate community features. This is important because, while the Americans with Disabilities Act requires these features be accessible (US Department of Justice, 2010), if the person with a disability perceives them to be inaccessible, then they will not use those features.

The highest rated community barrier was "lack of accessible transportation to fitness center." Inadequate transportation has been identified as a social determinant of health for people with disabilities (Krahn et al., 2015). By not having access to accessible transportation, people with disabilities are at risk for many of the chronic health conditions that were identified by DixonIbarra and Horner-Johnson (2014). Walking to public transportation could help physically inactive individuals meet the recommended levels of physical activity (Besser \& Dannenberg, 2005). The United States Surgeon General has called for communities to promote walking and walkable communities through the “Step It Up!” campaign (U.S. Department of Health and Human Services, 2015). One of the five strategic goals of Step It Up! is to "design communities that make it safe and easy to walk for people of all ages and abilities." In order to design a community that is inclusive of people with disabilities, researchers, public health practitioners, and urban/community planners should account for how people with disabilities rate community features.

\section{Limitations}

The primary limitation of this study is the use of self-reported physical activity, which might have led to inflated activity totals. The physical activity totals were different from what was found in other studies (Carroll et al., 2014). Objective measures of physical activity such as accelerometers have been used for people with 
disabilities, but they do not provide information about the type of physical activity. Future studies should explore the relationship between objective and subjective measures of physical activity with regard to community barriers to physical activity. This will allow researchers and public health practitioners the opportunity to have objective measures of physical activity with details into the type of physical activities that are performed. Additionally, researchers should explore how an intervention that addresses community barriers change physical activity levels and ratings for other community barriers post-intervention.

Another limitation is that the study results are not generalizable to all individuals with disabilities. People with disabilities who live in rural or suburban communities might have different barrier ratings. For example, lack of transportation was not a highly reported barrier because Chicago has access to a large public transit system that might not be available in rural communities. Because the study sample was relatively older and obese, it is difficult to generalize the findings to people with disabilities who are younger or are not obese. It is also difficult to separate the barriers that arise from the disability experience versus being older or obese. Future studies should examine how community barriers differ for people with disabilities living in other communities, and compare barriers between people with and without disabilities.

\section{Conclusion}

This study adds support to the impact that the community has on rates of physical activity. Efforts are being made to make communities universally accessible to people with disabilities. When compared to people with disabilities living in a neighborhood that did not have accessibility improvements, people with disabilities living in a community neighborhood where accessibility improvements were made had higher frequency of walking and participated in a more activities (Hallgrimsdottir, Svensson, \& Ståhl, 2015). This indicates that addressing accessibility can help increase physical activity levels. However further research is needed in understanding how people with disabilities rate community barriers.

\section{Acknowledgements}

This research was conducted when the author was a Postdoctoral Research Associate at the Institute on Disability and Human Development at the University of Illinois at Chicago. The project described was supported by a grant (Grant \# P30AG022849) from the National Institute on Aging. The content is solely the responsibility of the author and does not necessarily represent the official views of the National Institute on Aging or the National Institutes of Health.

\section{References}

Besser, L. M., \& Dannenberg, A. L. (2005). Walking to Public Transit: Steps to Help Meet Physical Activity Recommendations. American Journal of Preventive Medicine, 29(4), 273-280. doi:http://dx.doi.org/10.1016/j.amepre.2005.06.010

Botticello, A. L., Rohrbach, T., \& Cobbold, N. (2014). Disability and the built environment: an investigation of community and neighborhood land uses and participation for physically impaired adults. Annals of Epidemiology, 24(7), 545-550. doi:10.1016/j.annepidem.2014.05.003

Brownson, R., Baker, E., Housemann, R., Brennan, L., \& Bacak, S. (2001). Environmental and policy determinants of physical activity in the United States. American Journal of Public Health, 91(12), 1995-2003.

Carroll, D. D., Courtney-Long, E. A., Stevens, A. C., Sloan, M. L., Lullo, C., Visser, S. N., . . Dorn, J. M. (2014). Vital Signs: Disability and Physical Activity — United States, 2009-2012. Morbidity and Mortality Weekly Report, 63(18), 407-413.

Centers for Disease Control and Prevention. (2009). Fact sheet for health professionals on physical activity guidelines for adults. Retrieved from http://www.cdc.gov/nccdphp/dnpa/physical/pdf/PA_Fact_Sheet_Adults.pdf 
Vasudevan, V. / Californian Journal of Health Promotion 2016, Volume 14, Issue 1, 37-43.

Centers for Disease Control and Prevention. (2011). Physical activity for everyone: Glossary of terms. Retrieved from http://www.cdc.gov/physicalactivity/everyone/glossary/index.html

Centers for Disease Control and Prevention. (2015). Physical Activity and Health: The benefits of physical activity. Retrieved from http://www.cdc.gov/physicalactivity/basics/pahealth/index.htm

Christensen, K., Holt, J., \& Wilson, J. (2010). Effects of perceived neighborhood characteristics and use of community facilities on physical activity of adults with and without disabilities. Preventing Chronic Disease, 7(5), A105. doi:http://www.cdc.gov/pcd/issues/2010/sep/09_0179.htm.

Courtney-Long, E. A., Carroll, D. D., Zhang, Q. C., Stevens, A. C., Griffin-Blake, S., Armour, B. S., \& Campbell, V. A. (2015). Prevalence of Disability and Disability Type Among Adults - United States, 2013. Morbidity Mortality Weekly Report, 64(29), 777-783.

Dixon-Ibarra, A., \& Horner-Johnson, W. (2014). Disability Status as an Antecedent to Chronic Conditions: National Health Interview Survey, 2006-2012. Preventing Chronic Disease, 11, E15. doi:10.5888/pcd11.130251

Eisenberg, Y., Rimmer, J. H., Mehta, T., \& Fox, M. H. (2015). Development of a community health inclusion index: an evaluation tool for improving inclusion of people with disabilities in community health initiatives. BMC Public Health, 15, 1050. doi:10.1186/s12889-015-2381-2

Gray, J. A., Zimmerman, J. L., \& Rimmer, J. H. (2012). Built environment instruments for walkability, bikeability, and recreation: Disability and universal design relevant? Disability and Health Journal, 5(2), 87-101. doi:10.1016/j.dhjo.2011.12.002

Hallgrimsdottir, B., Svensson, H., \& Ståhl, A. (2015). Long term effects of an intervention in the outdoor environment - a comparison of older people's perception in two residential areas, in one of which accessibility improvements were introduced. Journal of Transport Geography, 42, 90-97. doi:http://dx.doi.org/10.1016/j.jtrangeo.2014.11.006

Krahn, G. L., Walker, D. K., \& Correa-De-Araujo, R. (2015). Persons With Disabilities as an Unrecognized Health Disparity Population. American Journal of Public Health, 105(S2), S198S206. doi:10.2105/AJPH.2014.302182

Rimmer, J., Riley, B., \& Rubin, S. (2001). A new measure for assessing the physical activity behaviors of persons with disabilities and chronic health conditions: The Physical Activity and Disability Survey. American Journal of Health Promotion, 16, 34-45.

Rosenberg, D. E., Huang, D. L., Simonovich, S. D., \& Belza, B. (2013). Outdoor Built Environment Barriers and Facilitators to Activity among Midlife and Older Adults with Mobility Disabilities. Gerontologist, 53(2), 268-279. doi:10.1093/geront/gns119

StataCorp. (2015). Stata Statistical Software: Release 14. College Station, TX: StataCorp LP.

U.S. Department of Health and Human Services. (2015). Step It Up! The Surgeon General's Call to Action to Promote Walking and Walkable Communities. Retrieved from Washington DC: http://www.surgeongeneral.gov/library/calls/walking-and-walkable-communities/call-to-actionwalking-and-walkable-communites.pdf

US Department of Justice. (2010). Guidance on the 2010 ADA Standards for Accessible Design. Retrieved from http://www.ada.gov/regs2010/2010ADAStandards/Guidance2010ADAstandards.htm

Vasudevan, V., Rimmer, J. H., \& Kviz, F. (2015). Development of the Barriers to Physical Activity Questionnaire for People with Mobility Impairments. Disability and Health Journal, 8(4), 547556. doi:10.1016/j.dhjo.2015.04.007

World Health Organization. (2001). The International Classification of Functioning, Disability and Health (ICF). Retrieved from Geneva http://www.who.int/classifications/icf/training/icfbeginnersguide.pdf 
Vasudevan, V. / Californian Journal of Health Promotion 2016, Volume 14, Issue 1, 37-43.

$\underline{\text { Author Information }}$

Vijay Vasudevan, Ph.D., MPH

Assistant Research Scientist

Department of Health Outcomes and Policy

University of Florida

PO Box 100177

Gainesville, FL 32610

vijay84@ufl.edu

* corresponding author 